\title{
Combined Reconstruction of the Medial Patellofemoral Ligament (MPFL) and Medial Quadriceps Tendon - Femoral Ligament (MQTFL) for Patellar Instability in Children and Adolescents: Surgical Technique and Outcomes
}

\section{Citation}

Redler, Lauren H., Robert C. Spang, Frances Tepolt, Eric A. Davis, and Mininder S. Kocher. 2017. "Combined Reconstruction of the Medial Patellofemoral Ligament (MPFL) and Medial Quadriceps Tendon - Femoral Ligament (MQTFL) for Patellar Instability in Children and Adolescents: Surgical Technique and Outcomes." Orthopaedic Journal of Sports Medicine 5 (7 suppl6): 2325967117S00387. doi:10.1177/2325967117S00387. http:// dx.doi.org/10.1177/2325967117S00387.

\section{Published Version}

doi:10.1177/2325967117S00387

\section{Permanent link}

http://nrs.harvard.edu/urn-3:HUL.InstRepos:34375112

\section{Terms of Use}

This article was downloaded from Harvard University's DASH repository, and is made available under the terms and conditions applicable to Other Posted Material, as set forth at http:// nrs.harvard.edu/urn-3:HUL.InstRepos:dash.current.terms-of-use\#LAA

\section{Share Your Story}

The Harvard community has made this article openly available.

Please share how this access benefits you. Submit a story.

Accessibility 


\title{
Combined Reconstruction of the Medial Patellofemoral Ligament (MPFL) and Medial Quadriceps Tendon - Femoral Ligament (MQTFL) for Patellar Instability in Children and Adolescents: Surgical Technique and Outcomes
}

\author{
Lauren H. Redler, MD ${ }^{1}$, Robert C. Spang, MD², Frances Tepolt, MD ${ }^{3}$, Eric A. Davis ${ }^{4}$, Mininder S. Kocher, MD, MPH \\ ${ }^{1}$ Columbia University - New York Presbyterian Hospital Program, New York, NY, USA, ${ }^{2}$ Harvard Combined Orthopaedic \\ Residency Program, Boston, MA, USA, '30ston Children's Hospital, Department of Orthopaedics (CERC), Boston, MA, USA, \\ ${ }^{4}$ Harvard Medical School, Boston, MA, USA, ${ }^{5}$ Boston Children's Hospital, Boston, MA, USA
}

Objectives: A variety of surgical options exist to treat the challenging problem of recurrent patellar instability in skeletally immature patients. The current study describes a combined reconstruction technique involving both the medial patellofemoral ligament (MPFL) and the medial quadriceps tendon - femoral ligament (MQTFL) and reports patient outcomes of a single-surgeon series.

Methods: All patients studied underwent combined MPFL and MQTFL reconstruction for patellar instability. Demographic data, pre- and post-operative radiographic data were collected. Reconstruction was performed using gracilis allograft. The graft midportion was fixed to the MPFL insertion on the femur via suture anchor. One arm of the graft (MPFL) was tunneled under medial retinaculum to the medial border of the patella and fixed there via suture anchor, while the other (MQTFL) arm was tunneled, delivered under the VMO and brought through the medial distal quadriceps tendon and sutured in place. Subjective outcome scores (Kujala, Pedi-IKDC, Lysholm) were collected via questionnaires mailed to patients more than one year from surgery.

Results: A total of 25 patients (27 knees), including 15 females and 10 males with an average age of $15.0 \pm 2.2$ years (range 10.3-18.9), underwent combined MPFL and MQTFL reconstruction. 6/25 (24\%) had undergone prior ipsilateral patellofemoral surgery for instability. 5/25 (20\%) underwent simultaneous guided growth via hemiepiphysiodesis for valgus deformity at the time of combined reconstruction. Preoperative imaging showed a mean TT-TG of $17.2 \pm 3.8$, Caton-Deschamps Index (CDI) of $1.13 \pm 0.16$, and trochlear dysplasia Dejour A/B (22/26 $(85 \%))$ or Dejour C/D (4/26 (15\%)). A total of 18 patients (19 knees, $72 \%)$ returned outcomes questionnaires at a mean $2.0 \pm 0.5$ years after surgery. Mean Kujala, Pedi-IKDC, and Lysholm scores were $85.9 \pm 13.9,81.5 \pm 15.2$, and $84.3 \pm 13.5$, respectively. $2 / 25$ patients $(8 \%)$ later required a revision procedure (tibial tubercle osteotomy) for recurrent patellar instability, and another patient reported persistent instability not requiring revision. 10/13 patients $(77 \%)$ were able to return to sports at a mean of $5.8+/-3.9$ months (range 2-15).

Conclusion: The current study describes a novel anatomically-validated surgical technique involving the simultaneous reconstruction of both the MPFL and MQTFL in a pediatric patient population. Follow-up data presented demonstrates overall positive results in treating this challenging problem in a young patient population.

The Orthopaedic Journal of Sports Medicine, 5(7)(suppl 6)

DOI: $10.1177 / 2325967117 S 00387$

(C)The Author(s) 2017

\footnotetext{
This open-access article is published and distributed under the Creative Commons Attribution - NonCommercial - No Derivatives License (http://creativecommons.org/licenses/by-nc-nd/3.0/), which permits the noncommercial use, distribution, and reproduction of the article in any medium, provided the original author and source are credited. You may not alter, transform, or build upon this article without the permission of the Author(s). For reprints and permission queries, please visit SAGE's Web site at http://www.sagepub.com/journalsPermissions.nav.
} 